\title{
O HOME QUE VIROU OFFICE: SAÚDE MENTAL NO MEIO AMBIENTE DO TRABALHO E O DIREITO À DESCONEXÃO NO CONTEXTO DE PANDEMIA
}

THE HOME THAT BECAME OFFICE: MENTAL HEALTH IN THE WORK ENVIRONMENT AND THE RIGHT TO DISCONNECT IN THE CONTEXT OF A PANDEMIC

Poliana Ribeiro Dos Santos ${ }^{1}$ Norma Sueli Padilha ${ }^{2}$

RESUMO: As medidas de contenção tomadas por órgãos da administração pública e privada entre os anos de 2020 e 2021, em decorrência da necessidade de contenção do avanço da pandemia de Covid-19, causaram reflexos na vida social e impactos em indústrias, empresas, comércios, turismo, governos e, principalmente, no modo de desenvolvimento da organização do trabalho. Com as alterações impulsionadas por conta do isolamento social, os trabalhadores ficaram condicionados a dividir o seu próprio espaço residencial com as atividades laborais, transformando, assim, o seu espaço de descanso e desconexão em meio ambiente do trabalho. Além disso, diante das tecnologias de informação e do controle exercido pelos empregadores, os trabalhadores passaram a desenvolver suas atividades em suas redes sociais particulares e por meio de redes de comunicação próprias (WhatsApp, email e redes sociais), tornando-se hiperconectado com o ambiente de trabalho. Apesar de haver previsão legal com relação a limitação da jornada de trabalho, essa não se verifica na nova modalidade de trabalho (home office), colocando em risco a saúde mental e física do trabalhador. Desse modo, a presente pesquisa visa abordar a relação entre meio ambiente do trabalho, hiperconexão laboral e saúde mental no contexto da pandemia de COVID-19. Busca-se, dessa forma, discutir os impactos da pandemia na saúde mental dos trabalhadores devido a hiperconexão laboral. Para tanto, a pesquisa se desenvolveu pelo método hipotéticodedutivo, aliado a técnicas de pesquisas bibliográficas e documentais.

Palavras-chave: Meio ambiente do trabalho; Home Office; Hiperconexão laboral; Direito à

\footnotetext{
${ }^{1}$ Doutoranda em Direito pelo Programa de Pós-Graduação em Direito da UFSC (PPGD/UFSC). Mestra em Direito pelo Programa de Pós-Graduação Profissional em Direito da Universidade Federal de Santa Catarina (PPGPD/UFSC). Currículo Lattes: http://lattes.cnpq.br/2149540920056487. Orcid: https://orcid.org/0000-0003-0698-2095. E-mail: polianaribeiro.prs@gmail.com

${ }^{2}$ Pós-doutora em Ética Ambiental pelo IFCH da Universidade Estadual de Campinas (UNICAMP). Doutora em Direito pela Pontifícia Universidade Católica de São Paulo (PUC/SP). Professora Adjunta da Universidade Federal de Santa Catarina (UFSC). Currículo Lattes: http://lattes.cnpq.br/7757445128600174. Orcid: https://orcid.org/0000-0001-7088-3767. E-mail: normasp@uol.com.br
} 
desconexão; Saúde mental.

ABSTRACT: The containment measures taken by public and private administration bodies between the years 2020 and 2021, as a result of the need to contain the advance of the Covid19 pandemic, caused reflexes on social life and impacts on industries, companies, commerce, tourism, governments and, mainly, in the way of development of the work organization. With the changes driven by social isolation, workers were conditioned to share their own residential space with work activities, thus transforming their space for rest and disconnection into a work environment. In addition, given the information technologies and the control exercised by employers, workers started to develop their activities in their private social networks and through their own communication networks (WhatsApp, email and social networks), becoming hyperconnected with the working environment. Although there is a legal provision regarding the limitation of working hours, this is not verified in the new type of work (home office), putting the worker's mental and physical health at risk. Thus, this research aims to address the relationship between the work environment, labor hyperconnection and mental health in the context of the COVID-19 pandemic. In this way, the aim is to discuss the impacts of the pandemic on the mental health of workers due to labor hyperconnection. Therefore, the research was developed using the hypotheticaldeductive method, combined with bibliographic and documentary research techniques.

Keywords: Work environment; Home Office; Work hyperconnection; Right to disconnect; Mental health.

Sumário: 1. Introdução; 2. A proteção jurídica da saúde mental do trabalhador; 3. Pandemia da covid-19: meio ambiente de trabalho e saúde mental do trabalhador; 4. A hiperconexão laboral e o direito a desconexão; 5. Considerações finais; 6. Referências.

\section{INTRODUÇÃO}

Em dezembro de 2019 ocorreu um surto patológico viral na cidade chinesa de Wuhan, que em poucos meses tomou proporção mundial. O vírus causador de uma grande crise sanitária foi identificado como SARS-CoV-2 e denominada como coronavírus (COVID-19). A transmissão do vírus ocorreu de forma muito veloz e letal, exigindo um combate agressivo e medidas estatais para preservação da vida humana (WORLD HEALTH ORGANIZATION, 2020, s.p.). Desse modo, com o objetivo de desacelerar e frear a transmissão da COVID-19, muitos países, inclusive o Brasil, adotaram medidas de contenção, como: isolamento social (quarentena), utilização de equipamentos de proteção (máscaras) e a redução de deslocamento urbano (THUNSTROM et al., 2020, s.p.).

A situação se agravou de maneira rápida, quando em 26 de fevereiro de 2020 o Ministério da Saúde do Brasil confirmou o primeiro caso de COVID-19. Em 04 de março de 
2020 foi decretado o estado de emergência nacional. E por fim em 11 de março de 2020 a Organização Mundial da Saúde (OMS) declarou a elevação do estado da contaminação à pandemia de COVID-19, doença causada pelo novo coronavírus.

As medidas de contenção da COVID-19 causaram reflexos na vida social e impactos (a curto, médio e longo prazo) em indústrias, empresas, comércios, escolas, universidades, turismos, governos e, principalmente, no modo de desenvolvimento do trabalho diário. Em virtude do isolamento social e da desconstrução da forma social até então posta, empregadores amargaram prejuízos financeiros, deterioração de estoques e, consequentemente, tiveram que reduzir o número de trabalhadores empregados, como também, precisaram alterar significativamente a forma de execução do labor (NASSIF; CORRÊA; ROSSETTO, 2020, p.15).

Outra consequência da COVID-19 e dessas medidas de contenção, especialmente no Brasil, foi o alto índice de desemprego, chegando a 13,5\% em 2020 e representando o maior número desde 2012 (IBGE, 2021, s.p.). Buscando a manutenção do emprego, da economia estatal e da preservação dos lucros, normas trabalhistas foram flexibilizadas para atender a situação de calamidade pública do país. Iniciando assim, de modo massivo, o trabalho na modalidade home office, remoto e o teletrabalho.

Nesse contexto de instabilidade econômica e movidos pelo temor de perder o emprego, um número exorbitante de trabalhadores brasileiros se sujeitaram ao trabalho em home office, abrindo a intimidade de seus lares para ali criar o seu meio ambiente laboral. Criou-se, desse modo, uma nova organização, em que o trabalhador é coagido a dividir o seu espaço residencial, seus equipamentos eletrônicos, suas instalações (energia elétrica, água e concectividade) e redes familiares para poder manter o emprego. O empregado, assim, perdeu seu espaço de conforto, descanso, unidade familiar e lazer, para operar sem qualquer retribuição a todas as perdas enumeradas.

Diante do desenvolvimento das atividades longe da empresa (remoto, teletrabalho ou home office), os empregadores comumente estabeleceram processos de controle e invasão de privacidade de seus trabalhadores, por meio de e-mails, whatsApp, telegram, instagram e até GPS, colocando o trabalhador na posição de hiperconectado e à disposição permanentemente do trabalho. 
Frente a todos esses fatores, a presente pesquisa visa abordar a relação entre meio ambiente do trabalho, hiperconexão laboral, saúde mental no contexto da pandemia causada pela COVID-19. Busca-se, nesse sentido, discutir os impactos da pandemia na saúde mental dos trabalhadores devido a hiperconexão laboral. Para tanto, a pesquisa se desenvolveu pelo método hipotético-dedutivo, aliado a técnicas de pesquisas bibliográficas e documentais.

\section{A PROTEÇÃO JURÍDICA DA SAÚDE MENTAL DO TRABALHADOR}

Antes de adentrar com maior profundidade sobre os tópicos principais do presente estudo, é essencial a construção de uma base sólida com relação ao histórico do tratamento jurídico a respeito da saúde do trabalhador. Desse modo, a presente pesquisa inicia com uma breve descrição sobre os principais diplomas legais, internacionais e nacionais, a respeito do direito a saúde mental dos trabalhadores.

A preocupação com o trabalhador, como um ser humano digno de direitos e proteções específicas, foi uma construção morosa, de muita luta e delicada. Destacam-se alguns marcos históricos significativos, tais como: a criação da Organização Internacional do Trabalho (OIT), com o Tratado de Versalhes (1919), a Organização das Nações Unidas (ONU), em 1945, a Organização Mundial da Saúde (OMS), em 1946, e a aprovação da Declaração Universal dos Direitos do Homem, em 1948.

Segundo Sebastião Geraldo de Oliveira (2011, p. 30) a preocupação com a saúde e condições de trabalho do trabalhador, passou por mudanças ao longo do tempo. Em cada etapa se desenvolvia uma compreensão mais ampla sobre todo o fenômeno que envolve a saúde do trabalhador, iniciando pela medicina do trabalho (1830), em que se observou a necessidade de manter trabalhadores sadios nas fábricas, com a finalidade de não prejudicar o processo produtivo. O objetivo se restringia em identificar trabalhadores doentes.

Com o fim da Segunda Guerra Mundial, as preocupações voltaram-se à saúde ocupacional (1950), em especial para a assistência médica do trabalhador, sem a intenção de prevenir acidentes de trabalho ou a-doenças ocupacionais. A terceira etapa se caracterizou pela atenção à saúde do trabalhador (1970), a partir da qual foram adotadas medidas e normatizações internacionais com o objetivo de prevenir acidentes e doenças do trabalho. Por fim, a última etapa histórica apresenta pelo autor consistiu na preocupação ampla com a 
qualidade de vida do trabalhador (1985), ou seja, pretende-se avançar para além da saúde do trabalhador: "busca-se a integração deste com o homem, o ser humano dignificado e satisfeito com a sua atividade, que tem vida dentro e fora do ambiente de trabalho, que pretende, enfim, qualidade de vida" (OLIVEIRA, 2011, p. 28).

Observa-se, assim, que houve um significativo processo de desenvolvimento a respeito da percepção legal e social sobre a saúde do trabalhador. Paulatinamente, deixou-se de lado o arcaico conceito de que saúde consistia apenas na ausência de doença, para um conceito amplo de "processo de equilíbrio entre corpo, mente e emoção, do qual resulta um estado de bem-estar integral do ser humano" (LEITE, 2003, p. 174).

Partindo dessa ampliação da abrangência do entendimento de saúde, em especial para a saúde mental, alguns diplomas merecem destaque e servirão de pilar para todo o desenvolvimento da contemporânea tese de abalo a saúde do trabalhador, pela hiperconexão.

O primeiro diploma que se destaca é o Pacto Internacional dos Direitos Sociais, Econômicos e Culturais, de 1966, o qual foi o primeiro documento internacional que se referiu ao direito ao meio ambiente saudável (GOLDSCHMIDT, 2020, p. 17). O aludido Pacto reconheceu, em seu artigo 12, item 2, alínea "b", "o direito de toda pessoa de desfrutar o mais elevado nível de saúde física e mental". Para tanto, estabeleceu que os Estados-partes deveriam adotar, com o fim de assegurar o pleno exercício desse direito, medidas que se façam necessárias para assegurar "a melhoria de todos os aspectos de higiene do trabalho e do meio ambiente" (PACTO, 1966, s.p.).

Outro diploma que merece destaque é a Convenção n. 155 da OIT, de 1981, tendo sido ratificada pelo Brasil em 1992. Esta certamente é uma das principais convenções que tratam da relação entre saúde do trabalhador e ambiente de trabalho. Já de início, a Convenção estabelece o que é saúde, de modo a abranger "não só a ausência de afecções ou de doenças, mas também os elementos físicos e mentais que afetam a saúde e estão diretamente relacionados com a segurança e a higiene no trabalho" (OIT, 1981, s.p.).

Além disso, tem-se a Convenção n. 161 da OIT, de 1985, ratificada pelo Brasil em 1990. Essa convenção determina os serviços de saúde do trabalho, para a proteção no meio ambiente de trabalho e que, logo no artigo $1^{\circ}$, incisos I e II, dispõe sobre os requisitos para "estabelecer e manter um ambiente de trabalho seguro e salubre, de molde a favorecer uma 
saúde física e mental ótima em relação com o trabalho" (OIT, 1985, s.p.), como também as necessárias adaptações "do trabalho às capacidades dos trabalhadores, levando em conta seu estado de sanidade física e mental" (OIT, 1985, s.p.).

Recentemente foi aprovada pela OIT a Convenção n. 190, 2019, durante a $108^{\mathrm{a}}$ Conferência Internacional do Trabalho. Há dois pontos de relevância social e jurídica nessa Convenção, especialmente voltadas para a saúde mental, sendo elas: a) a definição formal sobre as terminologias de "violência e assédio" e de "violência e assédio de gênero"; b) Foi utilizada a expressão world of work (tradução independente: mundo do trabalho), na versão em inglês, o que amplia a abrangência da aplicação da Convenção, inclusive para home office e outras configurações modernas quanto a modalidade de local de trabalho, não se restringindo ao "chão de fábrica".

Até outubro de 2021 o Brasil não havia ratificado a Convenção n. 190/2019 da OIT. No entanto, diante de tamanha relevância para a construção histórica e social da citada, faz jus a citação ipsis litteris, para servir de pilar ao presente estudo:

Article 1: 1. For the purpose of this Convention: (a) the term "violence and harassment" in the world of work refers to a range of unacceptable behaviours and practices, or threats thereof, whether a single occurrence or repeated, that aim at, result in, or are likely to result in physical, psychological, sexual or economic harm, and includes gender-based violence and harassment; (b) the term "genderbased violence and harassment" means violence and harassment directed at persons because of their sex or gender, or affecting persons of a particular sex or gender disproportionately, and includes sexual harassment. (OIT, 2019, s.p.)

Ainda no reduto da OIT, há algumas Convenções e Recomendações que merecem evidência, pois são de grande relevância para a construção do atual contexto social e jurídico relacionado ao entendimento da saúde integral do trabalhador, com reflexos inerentes à saúde mental, como: I) a Recomendação no 194, de 2002, que contempla um anexo com uma lista de enfermidades profissionais revisadas em 2010, no qual dedica um tópico exclusivamente aos transtornos mentais e de comportamento, associadas ao desenvolvimento de trabalho: "2.4. Transtornos mentais e comportamentais, 2.4.1. Transtorno de estresse pós-traumático, 2.4.2. Outros transtornos mentais ou comportamentais não mencionados no ponto anterior (...)" (OIT, 2002); II) a Convenção n. 
187, de 2006, sobre o marco promocional para a segurança e saúde no trabalho; III) a Convenção n. 184, de 2001, sobre a segurança e saúde na agricultura; IV) a Recomendação n. 160, de 1979, sobre segurança e saúde (trabalho portuário); V) a Recomendação n. 164, de 1981, sobre segurança e saúde ocupacional; VI) a Recomendação n. 171, de 1985, sobre serviços de saúde ocupacional; VII) Recomendação n. 175, de 1988, sobre segurança e saúde na construção; VIII) a Recomendação n. 183, de 1995, sobre segurança e saúde em minas; IX) a Recomendação n. 192, de 2001, sobre segurança e saúde na agricultura; e X) a Recomendação n. 197, de 2006, sobre estrutura promocional para segurança e saúde ocupacional.

Ainda no contexto internacional, outros dois diplomas merecem ênfase, considerando a saúde mental especificamente, tendo, inclusive, servido como base para Convenções da OIT. O primeiro deles consiste na Constituição da Organização Mundial da Saúde (OMS), de 1946, que em seu preâmbulo e no artigo $2^{\circ}$ dispõe expressamente que a "saúde é um estado de completo bem-estar físico, mental e social, e não consiste apenas na ausência de doença ou de enfermidade" (OMS, 1946, s.p.). Apesar do conceito de saúde da OMS estar definido desde 1946, apenas nas últimas décadas que tal entendimento elastecido de fato alcançou o mundo do trabalho, sendo ainda uma luta de reivindicações de trabalhadoras e trabalhadores no Brasil e em outros países. Observa-se, também, que diferente do mundo jurídico, a área da saúde há décadas compreende a dimensão integral da saúde do ser humano e a importância do equilíbrio entre a saúde mental e física (PEREIRA, 2019, p. 25).

Por fim, o último diploma internacional de destaque consiste na Convenção Americana Sobre Direitos Humanos, de 1969. Nela, em seu artigo 5 ${ }^{\mathrm{a}}$, trata-se sobre o Direito à integridade pessoal, dispondo expressamente sobre a previsão da integridade psíquica, como: "toda pessoa tem o direito de que se respeite sua integridade física, psíquica e moral" (OEA, 1969, s.p.).

No reduto jurídico brasileiro igualmente há previsão legal para a proteção da saúde integral do trabalhador, incluindo a saúde mental. Ao longo do presente estudo serão trabalhados com profundidade alguns deles, cabendo apenas aqui destacar, primeiramente, a própria Constituição da República Federativa do Brasil de 1988 , que já no artigo $5^{\circ}$ insere a saúde e o trabalho com direitos fundamentais. $\mathrm{O}$ artigo $7^{\circ}$, por sua vez, traz em seus incisos 
a proteção direta e específica a saúde do trabalhador e do meio ambiente de trabalho. $\mathrm{O}$ artigo 200, o qual vincula o Sistema Único de Saúde (SUS) ao meio ambiente de trabalho e, também, dispõe expressamente sobre a terminologia do meio ambiente do trabalho. E, por fim, o artigo 225, que traz a previsão do meio ambiente ecologicamente equilibrado.

Em seguida, vale destacar a Lei n. 8.080/1990, que estabeleceu o meio ambiente, o trabalho e o bem-estar mental do trabalhador como um complexo essencial para determinar e condicionar a saúde. Dá-se especial ênfase ao artigo $2^{\circ}$, que inclui o bem-estar mental como um direito fundamental e ao seu artigo $6^{\circ}$, que inclui no campo de atuação do SUS a execução de ações sobre a saúde do trabalhador. Em seguida, destaque ao artigo $3^{\circ}$, o qual dispõe que “Os níveis de saúde expressam a organização social e econômica do País, tendo a saúde como determinantes e condicionantes, entre outros, a alimentação, a moradia, o saneamento básico, o meio ambiente, o trabalho, a renda, a educação, a atividade física, o transporte, o lazer e o acesso aos bens e serviços essenciais" (BRASIL, 1990, s.p.)

Na mesma direção, tem-se o Decreto n. 3.048/1999, que aprova o regulamento da Previdência Social e o Decreto-Lei n. 5.452/1943, que aprova a Consolidação das Leis do Trabalho, ambos com previsão de adoecimento psíquico vinculado ao meio ambiente de trabalho e ao exercício de atividades laborais. Assim, diante da grande preocupação social com a saúde dos trabalhadores, pilares sociais, o ordenamento jurídico brasileiro possui um denso e extenso arsenal de normas para a preservação e prevenção da saúde integral do trabalhador.

\section{PANDEMIA DA COVID-19: MEIO AMBIENTE DE TRABAlHO E SAÚDE MENTAL DO TRABALHADOR}

Em dezembro de 2019 ocorreu um surto patológico viral na cidade chinesa de Wuhan, que em poucos meses tomou proporção mundial. Aludido surto, que viria a ser chamado de pandemia de COVID-19, acarretou a morte de mais de 4 milhões de pessoas até dezembro de 2020, infectando centenas de milhões de outras. A transmissão do vírus ocorreu de forma muito rápida e facilitada, exigindo um combate agressivo e medidas estatais para preservação da vida humana (WORLD HEALTH ORGANIZATION, 2020, s.p.). Desse modo, com o objetivo de desacelerar e frear a transmissão da COVID-19, grande parte dos 
países, inclusive o Brasil, adotaram políticas sociais na tentativa de reduzir os índices de contaminação. Entre as medidas adotadas, citam-se o isolamento e a quarentena, sendo esta uma forma de impedir a transmissão por meio da restrição de determinadas atividades (FERNEDA; COSTA, 2020, 13.), como a proibição de aglomerações em locais fechados, por exemplo. No entanto, vale salientar que as políticas de contenção não foram unificadas no Brasil, não partiram exclusivamente do Governo Federal e não se deram em consonância com a urgência que a situação exigia.

As medidas de contenção do vírus causaram reflexos na vida social e impactos (a curto, médio e longo prazo) em indústrias, empresas, comércios, turismo, governos e principalmente no modo do desenvolvimento do trabalho diário. Em virtude do isolamento social e da desconstrução da forma social até então posta, empregadores amargaram prejuízos financeiros, deterioração de estoques e consequentemente tiveram que reduzir o número de trabalhadores empregados, como também, alterar significativamente a forma de execução do labor (NASSIF, CORRÊA; ROSSETTO, 2020, p. 19).

O isolamento social impactou a forma como a sociedade percebe a vida, trazendo incertezas e inseguranças na manutenção do emprego e da renda. Consequentemente, colocou os trabalhadores em situação de hipervulnerabilidade, com dificuldades para a manutenção de seus próprios recursos materiais e financeiros, colocando em risco a conservação de elementos básicos como alimentação, moradia e saúde (mental e física). $\mathrm{O}$ temor do desemprego e a instabilidade financeira e econômica do país representaram uma situação propícia ao trabalhador, em posição de fragilidade, para aceitar condições de trabalho que colocassem em risco a sua integridade física e mental (BARROS-DELBEN et al., 2020, p. 09).

Diante de todo o contexto de pandemia, isolamento social, déficit econômico do país e prejuízos financeiros das indústrias, o governo brasileiro adotou um pacote de medidas para manutenção do emprego, renda e economia estatal. Destaca-se que o foco não foi a proteção da vida, e sim do capital. A manutenção do emprego e da produtividade das indústrias e empresas em meio a um surto de morte. Em suma, tais medidas buscaram flexibilizar a legislação trabalhista durante o período de pandemia, tais como as Medidas Provisórias (MP) n. 927 e a 1.046, de 2020, que trouxeram a possibilidade do teletrabalho, 
da antecipação de férias individuais, da concessão de férias coletivas, do aproveitamento e da antecipação de feriados, do banco de horas, da suspensão de exigências administrativas em segurança e saúde no trabalho, do direcionamento do trabalhador para qualificação e do diferimento do recolhimento do fundo de garantia do tempo de serviço.

Dentre as medidas provisórias editadas no período, outras duas de grande relevância sobre a flexibilização das normas trabalhistas foram as Medidas Provisórias n. 936 e a 1.045, de 2020. Ambas as medidas trouxeram a possibilidade de implementação do programa emergencial de manutenção do emprego e da renda, do benefício emergencial de preservação do emprego e da renda, da redução proporcional de jornada de trabalho e de salário, da suspensão temporária do contrato de trabalho.

Frente ao novo cenário econômico, social e legislativo (normas de flexibilização) houve um aumento repentino de trabalhos em home office, remoto, teletrabalho e outras configurações de execução das atividades laborais até então não convencionais, ou não difundidas. Subitamente os trabalhadores foram "atropelados por enxurradas" de informações sobre Novas Tecnologias de Informação e Comunicação (NTIC), por reuniões em videoconferência, por novos aplicativos e recursos online. Recursos tecnológicos até então utilizados para o lazer e contatos familiares, passaram a constituir ferramentas elementares para o desenvolvimento laboral, tais como: whatsApp, telegram, instagram, facebook, entre outros. O espaço residencial, familiar e de descanso passou a ser compartilhado com o trabalho, não havendo mais uma distinção entre o local sobre onde começa o espaço do trabalho e onde começa o espaço familiar, de lazer e descanso (SMITH; JUDD, 2020, p. 07).

A vida pessoal do trabalhador começou a integrar a vida profissional e vice-versa, não havendo mais marcadores de distanciamento entre as duas modalidades, muitas vezes confundindo-as. O meio ambiente residencial virou o meio ambiente do trabalho, sem investimento patronal no espaço físico, atenção à ergonomia, ventilação e iluminação. Nesse aspecto, pouco importou se o trabalhador teria ou não espaço físico residencial para o labor: o home office foi instituído sem qualquer tipo de consulta. $\mathrm{O}$ espaço físico para o desenvolvimento das atividades laborais é o mesmo onde o trabalhador dorme, se alimenta, cuida dos filhos, descansa e desenvolve atividades de lazer. Os aparelhos tecnológicos 
(celular, computador, tablets etc.) até então utilizados para a vida privada, passaram a ser utilizados como instrumentos de trabalho, compartilhando no mesmo local informações pessoais/privadas com aplicativos e software laboral. Até mesmo o tempo a disposição do empregador alterou sobremaneira em que, sob manto da falácia de horário flexível em home office, o trabalhador fica disponível em tempo integral, com intervenções e fiscalizações de superiores, clientes e prestadores de serviço.

Diante desse novo contexto de desenvolvimento das atividades laborais, questionase: há riscos para a saúde mental dos trabalhadores? Como preservar o equilíbrio integral do bem-estar físico, mental e social do trabalhador? Como proteger o direito ao descanso e ao meio ambiente equilibrado? Considerando que durante a pandemia da COVID-19 houve um repentino e significativo aumento de trabalho desenvolvido em home office, o presente estudo se debruçará sobre essa modalidade.

O primeiro fator de destaque a ser aqui analisado é o local de desenvolvimento das atividades laborais durante a pandemia (home office), ou seja, a residência dos trabalhadores. De acordo com Padilha e Pietro (2017), um ambiente do trabalho equilibrado é aquele "dotado de higidez e salubridade, apto a preservar a saúde e a segurança do trabalhador, assegurando-lhe qualidade de vida" (PADILHA; PIETRO, 2017, p. 533). Ainda, segundo as autoras, apenas com a preservação da vida e da integridade da saúde (física e mental) do trabalhador, é possível conceber o trabalho decente.

Nos termos da Constituição Federal do Brasil, de 1988, o ambiente de trabalho é considerado equilibrado quando contribuir para a sadia qualidade de vida. Ou seja, garantir um ambiente de trabalho livre de riscos a integridade física não é suficiente, sendo imprescindível um ambiente de trabalho sadio e que promova também a qualidade psíquica da vida do trabalhador. No mesmo entender Ney Maranhão (2016) conceitua o meio ambiento do trabalho como o resultado da "interação sistêmica de fatores naturais, técnicos e psicológicos ligados às condições de trabalho, à organização do trabalho e às relações interpessoais" a qual condiciona a "segurança e a saúde física e mental do ser humano exposto a qualquer contexto jurídico-laborativo" (MARANHÃO, 2016, p. 112).

A saúde mental e física do trabalhador está em evidência quando analisado o meio ambiente laboral. No contexto da pandemia da COVID-19 e do desenvolvimento da 
atividade laboral em home office, há uma estreita relação entre local de lazer, descanso, afeto, privacidade e vida familiar com o meio ambiente de trabalho. Isso, por sua vez, afeta a saúde mental do trabalhador, que não consegue usufruir do descanso, desconectar do mundo do trabalho e ainda tem a sua privacidade constantemente violada pelo trabalho. Percebe-se, dessa forma, a precarização do meio ambiente do trabalho e o adoecimento mental e físico do trabalhador (BARROS, et al., 2020, p. 15).

Pesquisas, especialmente no âmbito da saúde, já apontam para reflexos incidentes na saúde mental do trabalhador em virtude do atual modelo laboral, como: estresse, ansiedade, depressão, síndrome de Burnout, transtorno do estresse pós-traumático, desatenção pelo excesso de trabalho, síndrome do pânico e até o aumento considerável de dependência alcoólica e de outras drogas (SMITH, et al., 2020, p. 08; THUNSTROM, et al., 2020, p. 05; NASSIF, et al., 2020, p. 15; BARROS-DELBEN, et al., 2020, p. 09; VIGO, et al., 2020, p. 07).

Tais fatores demonstram indícios de que o meio ambiente laboral em home office, durante a pandemia, não preservou o direito constitucional ao meio ambiente de trabalho equilibrado e não contribuiu para a sadia qualidade de vida. Considerando que a tendência global é se adaptar a esse novo modelo de trabalho, recai grande preocupação quanto a preservação da saúde e dos direitos dos trabalhadores.

\section{A HIPERCONEXÃO LABORAL E O DIREITO A DESCONEXÃO}

Antes mesmo da pandemia da COVID-19 o mundo já experimentava as felicidades e os efeitos das Novas Tecnologias de Informação e Comunicação (NTIC), que dia após dia se tornaram artigos essenciais na vida social, na organização do trabalho, no desenvolvimento socioeconômico e na produção bens e serviço. Na última década as NTIC foram, paulatinamente, se tornando indispensáveis. Foram incorporadas ao cotidiano questões simples, como agenda telefônica, até as que exigem maior complexidade, como investimento na bolsa de valores ou até gerenciamentos bancários. Tudo com acesso facilitado e na palma da mão, pela distância de um clique.

Em 2017, a OIT e a Fundação Europeia para a Melhoria das Condições de Vida e de Trabalho (EUROFOUND, 2017, p. 01 - 50) realizou um estudo com 15 países, sobre as 
condições e os efeitos do teletrabalho e do trabalho móvel. A pesquisa apontou crescimento para essas modalidades de trabalhos nos países pesquisados. Além disso, apontou para os seguintes impactos: I - vantagens: incluem a redução do tempo de deslocamento, maior autonomia do horário de trabalho e maior produtividade. II - Desvantagens: incluem a tendência de prolongar a jornada de trabalho, de criar interferência entre o trabalho e a vida pessoal, e resultar na intensificação do trabalho, o que pode levar a altos níveis de estresse com consequências negativas para a saúde e o bem-estar dos trabalhadores.

Ainda, o resultado da pesquisa chamou atenção para a hiperconectividade laboral. A título de exemplo, na Espanha, 64\% dos trabalhadores confirmaram que desenvolvem atividades profissionais mesmo durante suas horas livres, de descanso e de folga. Sendo que $68 \%$ confirmaram que recebem com muita frequência e-mails e telefonemas relativos ao trabalho fora do horário de trabalho. Nos Estados Unido a realidade se mostrou semelhante: constatou-se que $44 \%$ dos americanos verificam seus e-mails institucionais diariamente, durante as férias e $54 \%$ responderam que mesmo afastados do trabalho por doença, continuam respondendo e-mails e chamados por meios digitais.

A citada pesquisa foi realizada antes mesmo da pandemia da COVID-19 e dos efeitos do isolamento social. A pesquisa revelou a tendência global para a hiperconexão laboral mesmo que de trabalhos não digitais, não remotos, não home office e não tele presenciais.

Há grandes riscos da hiperconectividade laboral causar danos psicológicos ao trabalhador, justamente por não promover um ambiente de trabalho equilibrado e a devida desconexão das matérias ligadas à esfera profissional. Os impactos na saúde do trabalhador são inúmeros, podendo surgir a curto, médio e longo prazo. Referidos impactos podem variar de sofrimento mental generalizado à estresse, ansiedade, depressão, síndrome de Burnout, transtorno do estresse pós-traumático, desatenção pelo excesso de trabalho, entre outras psicopatologias ocupacionais (THUNSTROM, et al., 2020, p. 05; BARROS-DELBEN, et al., 2020, p. 09; VIGO, et al., 2020, p. 07).

Como visto, a problemática da hiperconectividade e da necessidade de regular o direito à desconexão não foi uma inovação causada pela pandemia da COVID-19. A dinâmica organizacional também acompanha a evolução digital e por tal já passava por processos de transformações. Tão certo que no Brasil já havia a previsão legal do 
teletrabalho, instituído pelas Leis n. 12.551/2011 e n. 13.467/2017. Porém, apesar de haver norma regulamentando a modalidade, ainda não havia número representativo, se comparado com a tradicional forma de prestação de trabalho, especialmente considerando atividades tradicionais, das quais não se vislumbrava a ideia imediata de mudança para o teletrabalho de modo massivo, como o caso de tribunais de justiça, profissionais da saúde e educação. Desse modo, apesar da pandemia da COVID-19 não ter sido a criadora da hiperconectividade laboral, foi a mola propulsora dessa problemática, de modo a descortinar uma lacuna legislativa que necessita de amparo legal.

Apesar das principais revoluções na esfera do trabalho, das transformações sociais e tecnológicas, o paradoxo social do trabalho continua o mesmo da revolução industrial: o empregador exige do trabalhador uma esgotante dedicação ao labor, não correspondente com o salário e os benefícios oferecidos (MAIOR, 2003, p. 03). Visa-se única e exclusivamente a obtenção progressiva e desenfreada de capital, ao empregador, sem consideração com a saúde, bem-estar e qualidade de vida do trabalhador.

Por outro prisma, especialmente no período de pandemia, os trabalhadores possuem receio do desemprego e de não ter condições de subsistência. Por isso, além de outros fatores, os trabalhadores se sujeitam a relações de trabalho degradantes e a disponibilidade integral ao empregador, mesmo sem receber horas extras ou adicionais, ainda que isso acarrete redução de sua qualidade de vida. Essa disponibilidade integral em prol do empregador, chamada aqui de hiperconectividade laboral, compreende em relativizar os direitos fundamentais, como: o direito ao lazer, à saúde e ao descanso. O reflexo disso é o adoecimento mental e diminuição da qualidade de vida do trabalhador, trazendo reflexos para a toda a sociedade (MAIOR, 2003, p. 04).

Nesse sentido, o direito à desconexão do trabalho objetiva simplesmente a manutenção da saúde mental do trabalhador através do cumprimento da legislação vigente. Ou seja, usufruir do direito ao descanso e à vida privada, nada além disso. Luiz Souto Maior (2003, p. 07) conceitua o direito à desconexão: "ao se falar em desconexão faz-se um paralelo entre a tecnologia, que é fator determinante da vida moderna, e o trabalho humano", objetivando vislumbrar "um direito do homem de não trabalhar, ou, como dito, metaforicamente, o direito a se desconectar do trabalho" (MAIOR, 2003, p. 07). O autor 
ainda esclarece que:

O não-trabalho aqui referido não é visto no sentido de não trabalhar completamente e sim no sentido de trabalhar menos, até o nível necessário à preservação da vida privada e da saúde, considerando-se essencial esta preocupação (de se desligar, concretamente, do trabalho) exatamente por conta das características deste mundo do trabalho marcado pela evolução da tecnologia, pela deificação do Mercado e pelo atendimento, em primeiro plano, das exigências do consumo (MAIOR, 2003, p. 09).

$\mathrm{Na}$ mesma linha, António Monteiro Fernandes (2019) entende por direito à desconexão "os períodos em que o trabalhador não tem qualquer obrigação contratual de disponibilidade e visa garantir que o descanso e lazer sejam integralmente respeitados" (FERNANDES, 2019, p. 19). Ou seja, o direito à desconexão prevê simplesmente a fruição dos direitos constitucionais e trabalhistas, os direitos fundamentais.

O Brasil não possui uma legislação específica sobre o assunto, ou, utilizando a nomenclatura "desconexão" e/ou "hiperconexão". No entanto, os debates sobre essa temática são recentes, tendo recebido grande repercussão a partir da pandemia da COVID-19. Atualmente, apenas quatro países possuem legislação expressa e específica sobre essa temática, sendo: França, Itália, Bélgica e Espanha. Além disso, recentemente (janeiro/2021), o Parlamento Europeu aprovou o Relatório n. 2019/218, que estipula diretrizes e estimula a criação de leis pelos Estados-Membros, no âmbito do direito a desconexão (UNIÃO EUROPEIA, 2021, s.p.).

A França foi o primeiro país a instituir no Código do Trabalho medidas expressas de efetivação ao direito à desconexão, mesmo antes do Relatório n. 2019/218 do Parlamento Europeu. Em 2014, a Ugict-CGT, principal organização sindical francesa, lançou uma campanha pelo direito à desconexão do trabalhador. A partir de então, foram realizadas consultas à população acerca desse direito. E, em 2016, foi publicada a Lei de Desconexão (Lei El Khomri).

Apesar dos avanços legislativos na Europa quanto a incluir expressamente no ordenamento jurídico a previsão do direito a desconexão, não há penalidades quanto ao seu descumprimento. Tampouco há um sistema previsto de fiscalização e denúncia, de modo a inviabilizar, na prática, a proteção desse direito. 
No Brasil já foram apresentados dois projetos de leis abrangendo o direito à desconexão. O primeiro deles foi o Projeto de Lei n. 6.038, de 2016, que não foi aprovado. O segundo, consiste no Projeto de Lei n. 4.044, de 2020, que ainda está em tramite legislativo, porém, possui a mesma lacuna das leis europeias.

Por fim, em quaisquer projetos que busquem alterar formas e relações de trabalho e emprego, é necessário ter em mente aquilo que o antropólogo Studs Terkel (1972, p. 25) já lecionava: o trabalho representa a "busca por um sentido diário, bem como pelo pão de cada dia, por reconhecimento, bem como por dinheiro, por surpresa ao invés de torpor". Trata-se de um tipo de vida, e não de um tipo de morte, e adoecimento, de segunda a sexta.

\section{CONSIDERAÇÕES FINAIS}

As atuais legislações internacionais e nacionais são muito bem estruturadas para alcançar a tutela dos direitos dos trabalhadores, especialmente os condizentes à limitação da carga horária, limitação da jornada de trabalho e da fruição do descanso. Também há um vasto arsenal legislativo de proteção à saúde mental e física do trabalhador.

No entanto, apesar da admirável estrutura legislativa e da previsão desses direitos na Constituição da República (1988), não há um método de fiscalização real do trabalho executado, especialmente aquele desempenhado em home office, remoto ou telepresencial. Ao longo da relação de trabalho é comumente observado que o empregado é condicionado, pelo empregador, a se manter hiperconectado para atender as demandas laborais, mesmo que em seus períodos de descanso e fora do ambiente de trabalho, conforme inclusive demonstrou a pesquisa da OIT e da Fundação Europeia para a Melhoria das Condições de Vida e de Trabalho (EUROFOUND, 2017, p. 01 - 50), realizada em 2017.

Conforme demonstrado ao longo da presente pesquisa, a situação de exploração do trabalhador ficou ainda mais delicada e intensa após a pandemia da COVID-19 e a necessidade de instituir o trabalho em home office. A partir desse momento a residência do trabalhador, local até então de descanso, desconexão, de lazer e de conexão familiar, passou a ser uma extensão do meio ambiente de trabalho. Ceifou-se, dessa forma, toda a possibilidade do trabalhador de buscar momentos de total "desligamento" dos assuntos laborais. 
Condicionar o trabalhador a viver imerso 24 horas por dia dentro do seu meio ambiente de trabalho pode impactar em sua saúde mental. Observou-se que a hiperconexão com tecnologias de comunicação do labor podem acarretar a incidência de estresse, ansiedade, depressão, síndrome de Burnout, transtorno do estresse pós-traumático, desatenção pelo excesso de trabalho, síndrome do pânico e até o aumento considerável de dependência alcoólica e de outras drogas (SMITH, et al., 2020, p. 08; THUNSTROM, et al., 2020, p. 05; NASSIF, et al., 2020, p. 15; BARROS-DELBEN, et al., 2020, p. 09; VIGO, et al., 2020, p. 07).

Sendo assim, observou-se uma lacuna legislativa quanto a temática, assim como, que o direito à desconexão é uma garantia que deve ser expressamente tutelada e fiscalizada pelo estado, considerado como extensão dos direitos fundamentais, com o objetivo de preservar a saúde do trabalhador, refletindo na economia e em outros setores sociais.

\section{REFERÊNCIAS}

BARROS, Marilisa Berti de Azevedo et al. Relato de tristeza/depressão, nervosismo/ansiedade e problemas de sono na população adulta brasileira durante a pandemia de COVID-19. Epidemiologia e Serviços de Saúde, v. 29, p. e2020427, 2020. Disponível em: https://doi.org/10.1590/S1679-49742020000400018. Acesso em: 01 de nov. 2021.

BARROS-DELBEN, Paola et al. Saúde mental em situação de emergência: COVID-19. Debates em Psiquiatria, v. 10, n. 2, p. 18-28, 2020. http://dx.doi.org/10.25118/2236-918X10-2-3. Acesso em: 01 de nov. 2021.

BRASIL. Constituição da República Federativa do Brasil. 1988. Brasília, DF: Senado Federal: Centro Gráfico. Disponível em: http://www.planalto.gov.br/ccivil_03/constituicao/constituicao.htm. 01 de nov. 2021.

BRASIL. Decreto no 3.048/1999: aprova o Regulamento da Previdência Social, e dá outras providências. Disponível em: http://www.planalto.gov.br/ccivil_03/decreto/d3048.htm. Acesso em: 01 de nov. 2021.

BRASIL. Decreto-Lei $\mathbf{n}^{\mathbf{0}}$ 5.452/1943: aprova a Consolidação das Leis do Trabalho. Disponível em: http://www.planalto.gov.br/ccivil_03/decreto-lei/del5452.htm. Acesso em: 01 de nov. 2021.

BRASIL. Lei $\mathbf{N}^{\mathbf{0}} \mathbf{8 . 0 8 0}$, de 19 de setembro de 1990. Disponível em: http://www.planalto.gov.br/ccivil_03/leis/18080.htm. Acesso em: 01 de nov. 2021. 
BRASIL. Medida Provisória $\mathbf{N}^{\mathbf{0}}$ 927, de 22 de Março de 2020. Disponível em: https://www.in.gov.br/en/web/dou/-/medida-provisoria-n-927-de-22-de-marco-de-2020249098775. Acesso em: 01 de nov. 2021.

BRASIL. Medida Provisória $\mathbf{N}^{\mathbf{0}}$ 936, de 1 de Abril de 2020. Disponível em: https://www.in.gov.br/en/web/dou/-/medida-provisoria-n-936-de-1-de-abril-de-2020250711934. Acesso em: 01 de nov. 2021.

BRASIL. Medida Provisória $\mathbf{N}^{\mathbf{1}}$ 1.046, de 27 de abril de 2021. Disponível em: https://www.in.gov.br/en/web/dou/-/medida-provisoria-n-1.046-de-27-de-abril-de-2021316265470. Acesso em: 01 de nov. 2021.

BRASIL. Medida Provisória $\mathbf{N}^{\mathbf{1}}$ 1.045, de 27 de abril de 2021. Disponível em: https://www.in.gov.br/en/web/dou/-/medida-provisoria-n-1.045-de-27-de-abril-de-2021316257308. Acesso em: 01 de nov. 2021.

BRASIL. Projeto de Lei $\mathbf{n}^{\circ} \mathbf{4 0 4 4}$, de 2020. Disciplina o teletrabalho quanto às regras da jornada de trabalho, períodos de descanso e férias. Disponpivel em: https://www25.senado.leg.br/web/atividade/materias/-/materia/143754. Acesso em: 01 de nov. 2021.

BRASIL. Projeto de Lei n. 6.038, de 2016. Acrescenta o artigo 72-A à Consolidação das Leis do Trabalho (CLT), para dispor sobre o direito à desconexão do trabalho. Disponpivel em:

https://www.camara.leg.br/proposicoesWeb/prop_mostrarintegra;jsessionid=ABD82A2FF 00AD36D8C5EB537CBA80C1B.proposicoesWebExterno1 codteor $=1488226 \&$ filename= Avulso+-PL+6038/2016. Acesso em: 01 de nov. 2021.

COMISSÃO INTERAMERICANA DE DIREITOS HUMANOS (OEA). Convenção Americana sobre Direitos Humanos. Assinada na conferência especializada interamericana sobre direitos humanos, San José, Costa Rica, em 1969. Disponível em: https://www.cidh.oas.org/basicos/portugues/c.convencao_americana.htm. Acesso em: 01 de nov. 2021.

EUROFOUND, I. L. O. Working anytime, anywhere: The effects on the world of work. Luxembourg, Geneva, 2017. Disponível em: http://eurofound.link/ef1658. Acesso em: 01 de nov. 2021.

FERNANDES, António Monteiro. Direito do Trabalho, 19ª edição. Coimbra: Almedina, 2019.

FERNEDA, Ariê Sherreier. O trabalho decente e o meio ambiente do trabalho como forma de proteção da saúde mental do trabalhador. In: VILLATORE, Marco Antônio César; FERRAZ, Miriam Olivia Knopkik. (Org.). Fronteiras \& horizontes do direito do trabalho: resultados de pesquisa do Núcleo de Estudos Avançados em Direito do Trabalho e Socioeconômico. 1ed. Porto Alegre: Fi, 2019, p. 79-98. 
GOLDSCHMIDT, Rodrigo; GRAMINHO, Vivian Maria Caxambu. Desconexão: um direito fundamental do trabalhador. Rio de Janeiro: Lumen Juris, 2020.

INSTITUTO BRASILEIRO DE GEOGRAFIA E ESTATÍSTICA (IBGE). Desemprego chega a 14,7\% no primeiro trimestre, maior desde 2012. 2021. Disponível em: https://agenciadenoticias.ibge.gov.br/agencia-noticias/2012-agencia-denoticias/noticias/30793-desemprego-chega-a-14-7-no-primeiro-trimestre-maior-desde2012-e-atinge-14-8-milhoes-de-pessoas. Acesso em: 01 de nov. 2021.

LEITE, Roberto Basilone. Ecologia do Trabalho: simbiose entre o Direito do Trabalho e o Direito Ambiental. Revista do Tribunal Superior do Trabalho. Brasília, vol. 69, nº 1, jan/jun 2003.

MAIOR, Jorge Luiz Souto. Do direito à desconexão do trabalho. Revista do Direito Trabalhista, Brasília, v. 10, n. 09, p. 12-18, 2003. Disponível em: https://juslaboris.tst.jus.br/handle/20.500.12178/108056. Acesso em: 01 de nov. 2021.

MARANHÃO, Ney Stany Morais. Meio ambiente do trabalho: descrição jurídicoconceitual. Revista Direitos, Trabalho e Política Social, v. 2, n. 3, p. 80-117, 2016. Disponível em: http://revista91.hospedagemdesites.ws/index.php/rdtps/article/view/40. Acesso em: 17 de out. 2021.

NASSIF, V. M. J., CORRÊA, V. S., \& ROSSETTO, D. E. Estão Os Empreendedores E As Pequenas Empresas Preparadas Para As Adversidades Contextuais? Uma Reflexão À Luz Da Pandemia Do Covid-19. Revista de Empreendedorismo e Gestão de Pequenas Empresas, 2020. Disponível em: http://dx.doi.org/10.14211/regepe.v9i2.1880. Acesso em: 01 de nov. 2021.

OLIVEIRA, Sebastião Geraldo de. Proteção jurídica à saúde do trabalhador. São Paulo: LTr. 6a ed. 2011.

ORGANIZAÇÃO INTERNACIONAL DO TRABALHO (OIT). Convenção no.: 155 Segurança e Saúde dos trabalhadores. 1981. Disponível em: https://www.ilo.org/brasilia/convencoes/WCMS_236163/lang--pt/index.htm. Acesso em: 01 de nov. 2021.

ORGANIZAÇÃO INTERNACIONAL DO TRABALHO (OIT). Recomendação no 194. 2002. Disponível em: http://www.oitbrasil.org.br. Acessado em: 01 de nov. 2021.

ORGANIZAÇÃO INTERNACIONAL DO TRABALHO OIT (OIT). Convenção n⿳o: 161 - Serviços de Saúde do Trabalho. 1985. Disponível em: https://www.ilo.org/brasilia/convencoes/WCMS_236240/lang--pt/index.htm. Acesso em: 01 de nov. 2021.

ORGANIZAÇÃO INTERNACIONAL DO TRABALHO OIT (OIT). Convenção n⿳.: 190 - Violence and Harassment Convention. 2019. Disponível em: 
https://www.ilo.org/dyn/normlex/en/f?p=NORMLEXPUB:12100:0::NO::P12100_ILO_C ODE:C190. Acesso em: 01 de nov. 2021.

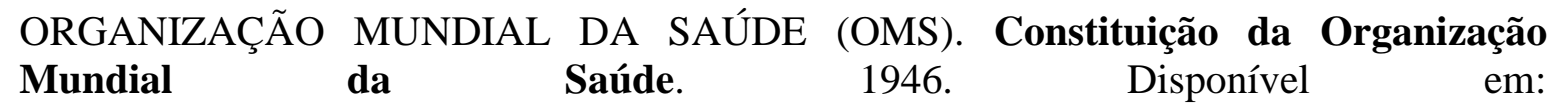
http://www.direitoshumanos.usp.br/index.php/OMS-Organiza\%C3\%A7\%C3\%A3oMundial-da-Sa\%C3\%BAde/constituicao-da-organizacao-mundial-da-saude-omswho.html. Acesso em: 01 de nov. 2021.

ORGANIZAÇÃO MUNDIAL DA SAÚDE (OMS). Coronavirus disease 2019 (COVID19): situation report-78. Geneva. 2020. Disponível em: https://www.who.int/docs/defaultsource/coronaviruse/situation-reports/20200407-sitrep78-covid-19.pdf?sfvrsn=bc43e1b_2. Acesso em: 01 de nov. 2021.

PACTO INTERNACIONAL DOS DIREITOS ECONÔMICOS, SOCIAIS E CULTURAIS. 1966. Disponível em: http://www.pge.sp.gov.br/centrodeestudos/bibliotecavirtual/instrumentos/direitos.htm. Acesso em: 01 de nov. 2021.

PADILHA, Norma Sueli; DI PIETRO, Josilene Hernandes Ortolan. A contribuição da OIT na construção da tutela internacional do direito ao meio ambiente do trabalho equilibrado. Revista da Faculdade de Direito da UFMG, n. 70, p. 529-560, 2017. Disponível em: https://doi.org/10.12818/P.0304-2340.2017v70p529. Acesso em: 01 de nov. 2021.

PEREIRA, André Sousa. Meio Ambiente do trabalho e o direito à saúde mental do trabalhador. São Paulo: LTr, 2019.

SMITH, James A.; JUDD, Jenni. COVID-19: vulnerability and the power of privilege in a pandemic. Health Promotion Journal of Australia, v. 31, n. 2, p. 158, 2020. Disponível em: https://doi.org/10.1002/hpja.333. Acesso em: 01 de nov. 2021.

TERKEL, Studs. Working. New York: Avon Books, 1972.

THUNSTROM, Linda et al. The benefits and costs of using social distancing to flatten the curve for COVID-19. Journal of Benefit-Cost Analysis, v. 11, n. 2, p. 179-195, 2020. Disponível em: http://dx.doi.org/10.2139/ssrn.3561934. Acesso em: 01 de nov. 2021.

UNIÃO EUROPEIA. European Parliament resolution of 21 January 2021 with recommendations to the Commission on the right to disconnect: 2019/2181(INL). Bruxelas. 2021. Disponível em: https://www.europarl.europa.eu/doceo/document/TA-92021-0021_EN.html. Acesso em: 01 de nov. 2021.

VIGO, Daniel et al. Mental health of communities during the COVID-19 pandemic. The Canadian Journal of Psychiatry, 1-7, 2020. Disponível em: https://doi.org/10.1177/0706743720926676. Acesso em: 01 de nov. 2021. 
WORLD HEALTH ORGANIZATION. Doença por coronavírus (COVID-19). 2020. Disponível em: https://www.who.int/health-topics/coronavirus\#tab=tab_1. Acesso em: 01 de nov. 2021.

Data da submissão: 23/11/2021

Data da primeira avaliação: 25/11/2021

Data da segunda avaliação: 10/12/2021

Data da aprovação: $10 / 12 / 2021$ 